\title{
Effect of fremanezumab on quality of life and productivity in patients with chronic migraine
}

Richard B. Lipton, MD, Joshua M. Cohen, MD, MPH, FAHS, Sanjay K. Gandhi, PhD, Ronghua Yang, PhD, Paul P. Yeung, MD, MPH, FAHS, and Dawn C. Buse, PhD

Neurology ${ }^{\circledR}$ 2020;95:e878-e888. doi:10.1212/WNL.0000000000010000

\author{
Correspondence \\ Dr. Lipton \\ Richard.Lipton@ \\ einstein.yu.edu

\section{MORE ONLINE} \\ $\rightarrow$ Class of Evidence \\ Criteria for rating \\ therapeutic and diagnostic \\ studies \\ NPub.org/coe
}

\section{Methods}

HALO CM was a double-blind, placebo-controlled trial in patients with CM. Patients were randomized 1:1:1 to treatment with fremanezumab quarterly (675 $\mathrm{mg}$ at baseline, placebo at weeks 4 and 8 ), fremanezumab monthly (225 $\mathrm{mg}$ at baseline, weeks 4 and 8 ), or placebo. This article assessed the effect of treatment with fremanezumab on health-related quality of life and productivity using the following prespecified assessments: the Migraine-Specific Quality of Life (MSQoL) questionnaire at baseline and weeks 4, 8, and 12; Patient Global Impression of Change (PGIC) questionnaire at weeks 4, 8, and 12; and EuroQoL 5-dimension, 5-response level (EQ-5D-5L) questionnaire and Work Productivity and Activity Impairment: General Health (WPAI:GH) questionnaire at baseline and week 12.

\section{Results}

The full analysis set included 1,121 patients: 375 patients with quarterly dosing, 375 with monthly dosing, and 371 with placebo. Fremanezumab quarterly and monthly was associated with significant improvements over placebo in change from baseline mean scores in MSQL domains (all, $p<0.05$ ) to week 12. At week 12, fremanezumab also showed significant improvements in EQ-5D-5L visual analog scale $(p<0.05)$ and PGIC scores $(p<0.0001)$ as well as significant reductions from baseline in WPAI:GH scores $(p<0.01)$ and presenteeism (impairment while working; $p<0.05$ ) vs placebo.

\section{Conclusions}

Fremanezumab quarterly or monthly was associated with improvement over placebo in migraine-specific quality of life, overall health status, patients' global impression of change with treatment, and productivity in patients with $\mathrm{CM}$.

\section{ClinicalTrials.gov identifier}

NCT02621931.

\section{Classification of evidence}

This study provides Class II evidence that in patients with CM, treatment with fremanezumab quarterly or monthly is associated with improvements in health-related quality of life and productivity. 


\section{Glossary}

$\mathbf{C M}=$ chronic migraine; $\mathbf{E M}$ = episodic migraine; EQ-5D-5L = EuroQoL 5-dimension, 5-response level; FAS = full analysis set; HIT-6 = 6-item Headache Impact Test; HRQoL = health-related quality of life; LSM = least-squares mean; MSQoL = Migraine-Specific Quality of Life; PGIC = Patient Global Impression of Change; VAS = visual analog scale; WPAI:GH = Work Productivity and Activity Impairment: General Health.

Migraine is ranked globally as the second-leading cause of years lived with disability and the leading cause in adults under the age of $50 .^{1-5}$ People with migraine experience substantially impaired daily functioning, associated disability, and reduced health-related quality of life (HRQoL). ${ }^{6,7}$ Those with chronic migraine (CM) have more comorbidities, including depression, anxiety, and cardiovascular disorders; have increased impairment of occupational, academic, financial, social, and family life; and contribute to a financial burden on health care systems and society through direct and indirect costs of the disease. ${ }^{8-12}$

Over the past decade, a few trials have targeted preventive treatment to individuals with CM. ${ }^{13,14}$ These studies typically assess reduction in monthly migraine or headache days as their primary endpoint ${ }^{15}$; however, they may not fully capture the benefits of preventive treatments, including improvements in quality of life and productivity. ${ }^{16}$ Validated and clinically relevant patient-reported outcome measures ${ }^{16-18}$ provide a patient-centric approach that more fully captures the effects of migraine on quality of life and supports betterinformed treatment decisions.

Fremanezumab (AJOVY [North Wales, PA]), a fully humanized monoclonal antibody (immunoglobulin G2 $\Delta \mathrm{a}$ ), selectively targets calcitonin gene-related peptide and is indicated for the preventive treatment of migraine in adults in the United States and European Union. ${ }^{19-21}$ The efficacy and safety of fremanezumab quarterly and monthly in $\mathrm{CM}$ were demonstrated in the placebo-controlled phase 3 HALO CM trial; this study met its primary outcome of a reduction in the monthly average number of headache days of at least moderate severity, as well as all prespecified secondary endpoints. ${ }^{22}$ Here we report the outcomes of prespecified exploratory endpoints, including HRQoL, general health status, patients' global impression of change, productivity, and activity impairment in patients with CM.

\section{Methods}

\section{Classification of evidence}

This interventional study provides Class II evidence that fremanezumab quarterly and monthly is associated with improvements in patient-reported outcomes of HRQoL, general health status, productivity, and activity impairment in patients with CM.

\section{Standard protocol approvals, registrations, and patient consents}

The HALO CM phase 3 study was conducted in full accordance with International Council on Harmonisation Good Clinical Practice Consolidated Guidelines, the principles of the Declaration of Helsinki, and all applicable national and local laws and regulations. It was registered at ClinicalTrials. gov as NCT02621931. All patients provided written informed consent before screening, and all protocols were approved by institutional review committees for each site. The studies were conducted from March 2016 through January 2017 at headache centers, neurology clinics, and primary care facilities at 132 sites in Canada, the Czech Republic, Finland, Israel, Japan, Poland, Russia, Spain, and the United States. Results from exploratory analyses of the HALO CM study are reported here.

\section{Study design}

The HALO CM methodology has been reported previously. ${ }^{22}$ Briefly, it was a 16-week, randomized, double-blind, placebo-controlled, parallel-group study. ${ }^{22}$ The trial consisted of a screening visit, a 28-day pretreatment period, a 12-week treatment period, and a final evaluation at week 12. Based on information from screening and an electronic daily headache diary captured during the pretreatment period, individuals were assigned to the current study for CM (ClinicalTrials.gov NCT02621931) or a concurrent study for episodic migraine (EM) (ClinicalTrials.gov NCT02629861); alternatively, they were excluded if they did not meet eligibility criteria for either study. ${ }^{22}$

Patients with CM were randomly assigned in a 1:1:1 ratio to receive fremanezumab quarterly, fremanezumab monthly, or placebo, administered as a subcutaneous injection. Fremanezumab quarterly dosing consisted of $675 \mathrm{mg}$ at baseline (three $225 \mathrm{mg} / 1.5 \mathrm{~mL}$ injections) and placebo (one $1.5 \mathrm{~mL}$ injection) at weeks 4 and 8 . Fremanezumab monthly dosing consisted of $675 \mathrm{mg}$ at baseline (three $225 \mathrm{mg} / 1.5 \mathrm{~mL}$ injections) and $225 \mathrm{mg}$ fremanezumab at weeks 4 and 8 (one $225 \mathrm{mg} / 1.5 \mathrm{~mL}$ injection). Placebo dosing consisted of placebo injections at baseline (three $1.5 \mathrm{~mL}$ injections) and at weeks 4 and 8 (one $1.5 \mathrm{~mL}$ injection). Randomization was performed with electronic interactive-response technology and patients were stratified according to sex, country, and baseline use of preventive medication (yes or no). Patients, investigators, the sponsor, and trial staff (except for those involved in bioanalytical analyses) were blinded to study group assignments. 


\section{Study participants}

Key inclusion criteria were an age of 18-70 years, a history of migraine (International Classification of Headache Disorders, third edition, beta version criteria) for at least 12 months, and the fulfillment of criteria for $\mathrm{CM}$ during the 28-day pretreatment period (headache of any duration or severity on $\geq 15$ days and headache for $\geq 8$ days meeting specific migraine criteria). Key exclusion criteria were the use of onabotulinumtoxinA in the 4 months before screening, the use of barbiturates on $>4$ days during the pretreatment period, and a lack of efficacy of $\geq 2$ of 4 specific clusters of migraine preventive treatments. The protocol permitted entry of a limited subset of patients who had been using a maximum of one preventive migraine medication, which had shown at least moderate evidence of efficacy, ${ }^{23}$ at a stable dosage for at least 2 consecutive months prior to screening.

\section{Study assessments}

All the endpoints assessed here were part of a prespecified exploratory analysis. The Migraine-Specific Quality of Life Questionnaire version 2.1 (MSQoL), assessed at baseline and at weeks 4,8 , and 12 , is a reliable and valid measure of migraine-specific HRQoL. The MSQoL assesses the effect of migraine on daily functioning in 3 domains: role function-restrictive, 7 items on how migraine limits daily activities; role function-preventive, 4 items on how migraine prevents these activities; and emotional function, 3 items on emotions associated with migraine. ${ }^{16}$ Raw domain scores are computed as a sum of item responses and rescaled from 0 to 100 , with higher scores indicating better HRQoL. ${ }^{16}$ The thresholds for minimally clinically important differences have been established as 3.2 for role function-restrictive, 4.6 for role function-preventive, and 7.5 for emotional function. ${ }^{24}$

The EuroQol-5 (EQ-5D-5L) standardized questionnaire, assessed at baseline and week 12, is a quantitative assessment of overall state of health. Patients are asked to rate their current general health state on a scale from 0 to 100 using a $20-\mathrm{cm}$ visual analog scale (VAS), with higher scores indicating better health. ${ }^{25}$

The Patient Global Impression of Change (PGIC) scale, assessed at weeks 4,8 , and 12 , is a validated tool to evaluate patients' impression of change in overall status after treatment. Patients are asked to self-evaluate their overall response to treatment by rating the effect that their migraine/headache have had on their general quality of life and health status since beginning the treatment. The assessment is based on a 7-point scale ( 1 , no change; 2 , almost the same; 3 , a little better; 4 , somewhat better; 5 , moderately better; 6 , better; 7 , a great deal better). ${ }^{26}$

The Work Productivity and Activity Impairment: General Health (WPAI:GH) questionnaire, assessed at baseline and week 12, is a 6-item validated instrument that reflects the effect of an individual's general health on the ability to work and perform regular activities as measured by absenteeism (work time missed), presenteeism (impairment while working), overall work productivity loss (composite of absenteeism and presenteeism), and activity impairment. ${ }^{17,27,28}$ Participants who self-identified as employed were eligible to complete all questionnaire items, whereas those not employed were eligible to complete only the activity impairment item. ${ }^{28}$ Outcomes are reported as impairment percentages, with higher values indicating greater impairment. ${ }^{27}$

\section{Statistical analysis}

Statistical analyses were performed in the full analysis set (FAS), which included all randomized patients who received $\geq 1$ dose of study drug and had $\geq 10$ days of postbaseline efficacy assessment on the primary endpoint. A sample size of 867 patients (289 patients per treatment group) provided at least $90 \%$ power for the study to succeed on the primary outcome at an $\alpha$ level of 0.05 . Assuming a $15 \%$ discontinuation rate, 340 patients per treatment group were randomized. Sample size calculations were not performed for this subgroup analysis.

MSQoL, EQ-5D-5L, and WPAI:GH scores were analyzed using an analysis of covariance approach, with years since onset of migraine and baseline measurements for the corresponding questionnaire as covariates. A mixed-effects repeated-measures analysis model (MMRM) was also used on MSQoL scores as a supportive analysis. For the PGIC, responses were divided into 2 categories: patients reporting a score of $\geq 5$ (moderately better to a great deal better) and those reporting a score of $\leq 4$ (no change to somewhat better). The percentages of patients reporting a score of $\geq 5$ and patients reporting a score of $\leq 4$ were analyzed using the Cochran-Mantel-Haenszel test stratified by baseline preventive migraine medication use.

\section{Data availability}

The data described in this report are available by request from the author investigators or Teva Pharmaceuticals Ltd., the company sponsoring the clinical development of fremanezumab for the treatment of migraine.

\section{Results}

\section{Patients}

The study was conducted from March 2016 through January 2017. In total, 1,130 patients were randomized to fremanezumab quarterly $(\mathrm{n}=376)$, fremanezumab monthly $(\mathrm{n}=$ $379)$, or placebo $(\mathrm{n}=375)$. Of these, 1,034 patients completed the trial: fremanezumab quarterly $(n=349$ [93\%]), fremanezumab monthly $(\mathrm{n}=343[91 \%])$, and placebo $(\mathrm{n}=$ 342 [91\%]) (figure 1). The FAS population included 1,121 patients: 375 patients with quarterly dosing, 375 with monthly dosing, and 371 with placebo.

Baseline patient demographics and clinical characteristics were similar among all treatment arms. On average, patients 


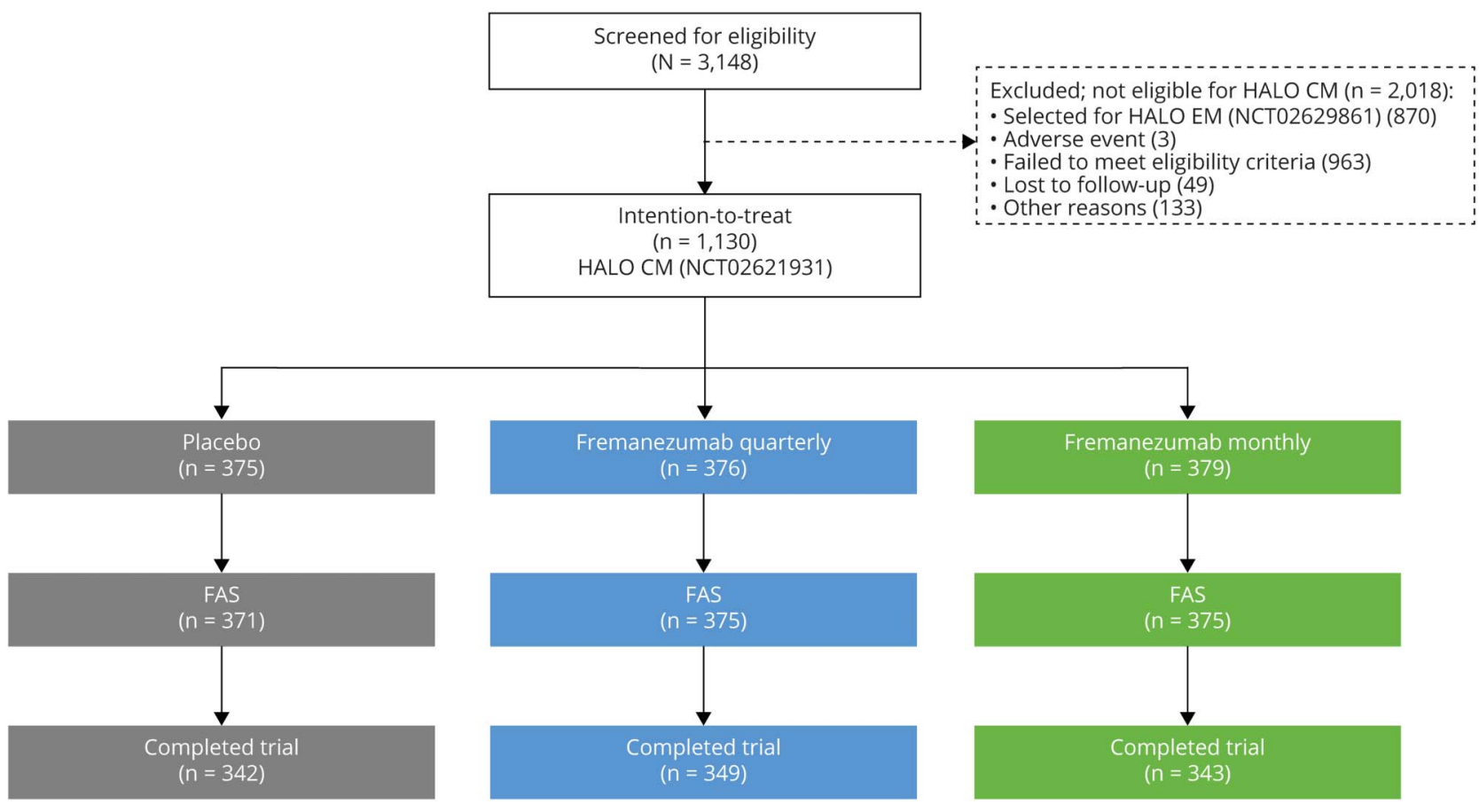

$\mathrm{CM}$ = chronic migraine; $\mathrm{EM}$ = episodic migraine; FAS = full analysis set.

were approximately 41 years of age, had a migraine diagnosis for approximately the last 20 years, and reported severe headache-related disability (6-item Headache Impact Test [HIT-6] scores > 60) (table).

\section{Improvement in HRQOL}

Fremanezumab was associated with clinically meaningful and statistically significant increases in the mean scores for each MSQoL domain (role function-restrictive [figure 2A], role function-preventive [figure $2 \mathrm{~B}$ ], and emotional function [figure $2 \mathrm{C}$ ]) from baseline (day 0 ) to the end of treatment (4 weeks after administration of the last dose) compared with placebo. At 4 weeks, the role function-restrictive least-squares mean (LSM) score changes were 19.1 and 19.4 for fremanezumab quarterly and monthly, respectively, vs 12.0 for placebo $(p<0.0001$ for both fremanezumab dosing regimens). At 12 weeks, the role function-restrictive LSM score changes were 20.3 and 21.0 for fremanezumab quarterly and monthly, respectively, vs 14.7 for placebo $(p<0.0001$ for both). For the role function-preventive score at 4 weeks, LSM changes were 15.3 and 15.8 for quarterly and monthly administration vs 9.4 for placebo $(p<0.0001$ for both fremanezumab dosing regimens). At 12 weeks, the role function-preventive LSM score changes were 15.9 and 15.5 for quarterly and monthly administration vs 11.6 for placebo (fremanezumab quarterly, $p=0.0007$; fremanezumab monthly, $p=0.0017$ ). At 4 weeks, the emotional function LSM score changes were 19.1 and 19.5 for quarterly and monthly administration, respectively, vs 12.1 for placebo ( $p<$ 0.0001 for both fremanezumab dosing regimens). At 12 weeks, the emotional function LSM score changes were 20.9 and 20.3 for quarterly and monthly administration vs 17.0 for placebo (fremanezumab quarterly, $p=0.0126$; fremanezumab monthly, $p=0.0348)$.

The above differences in the role function-restrictive and role function-preventive scores exceeded the threshold for minimally clinically important differences at 4 weeks for fremanezumab quarterly and monthly. The improvements in the role function-restrictive score for both dosing arms exceeded the minimally clinically important difference at 12 weeks. ${ }^{24}$

\section{Improvement in general health state}

Fremanezumab was associated with significantly improved overall health state, as measured by the EQ-5D-5L VAS score, from baseline (day 0 ) to 4 weeks after administration of the last dose of study drug, compared with placebo (figure 3 ). The LSM score changes were 4.6 and 4.8 for fremanezumab quarterly and monthly vs 2.2 for placebo (quarterly, $p=$ 0.0402; monthly, $p=0.0291$ ).

\section{Patient global impression of change}

Fremanezumab was associated with significantly greater proportions of patients who reported PGIC scores $\geq 5$ from the start of the study drug treatment, compared with placebo (figure 4). At 4 weeks, the percentage of patients reporting PGIC scores $\geq 5$ was $53 \%$ and $54 \%$ for quarterly and monthly fremanezumab administration vs $31 \%$ for placebo (fremanezumab quarterly, $p<0.0001$; fremanezumab monthly, $p<$ $0.0001)$; at 12 weeks, similar percentages of patients reporting 
Table Baseline patient demographics and clinical characteristics ${ }^{a}$

\begin{tabular}{|c|c|c|c|}
\hline \multirow[b]{2}{*}{ Characteristic } & \multirow[b]{2}{*}{ Placebo $(n=375)$} & \multicolumn{2}{|l|}{ Fremanezumab } \\
\hline & & Quarterly $(n=376)$ & Monthly $(n=379)$ \\
\hline Age, y & $41.4(12.0)$ & $42.0(12.4)$ & $40.6(12.0)$ \\
\hline $\mathrm{BMI}, \mathrm{kg} / \mathrm{m}^{2}$ & $26.5(5.0)$ & $26.6(5.4)$ & $26.5(5.1)$ \\
\hline Sex, female & $330(88)$ & $331(88)$ & $330(87)$ \\
\hline \multicolumn{4}{|l|}{ Migraine history } \\
\hline Time since initial migraine diagnosis, y & $19.9(12.9)$ & $19.7(12.8)$ & $20.1(12.0)$ \\
\hline Current use of preventive medication & $77(21)$ & $77(20)$ & $85(22)$ \\
\hline Current use of acute headache medication & $358(95)$ & $359(95)$ & $360(95)$ \\
\hline Prior use of topiramate & $117(31)$ & $106(28)$ & $117(31)$ \\
\hline Prior use of onabotulinumtoxinA & $49(13)$ & $66(18)$ & $50(13)$ \\
\hline \multicolumn{4}{|l|}{ Migraine characteristics during 28-day pretreatment period } \\
\hline Headache days ${ }^{b}$ & $13.3(5.8)$ & $13.2(5.5)$ & $12.8(5.8)$ \\
\hline Migraine days $^{c}$ & $16.4(5.2)$ & $16.2(4.9)$ & $16.0(5.2)$ \\
\hline Days of any acute headache medication use & $13.0(6.9)$ & $13.1(6.8)$ & $13.1(7.2)$ \\
\hline Days of migraine-specific acute headache medication use & $10.7(6.3)$ & $11.3(6.2)$ & $11.1(6.0)$ \\
\hline \multicolumn{4}{|l|}{ Disability measures } \\
\hline HIT-6 score ${ }^{d}$ & $64.1(4.8)$ & $64.3(4.7)$ & $64.6(4.4)$ \\
\hline \multicolumn{4}{|l|}{ Employment status } \\
\hline Currently employed & $288(77)$ & $272(72)$ & $277(73)$ \\
\hline
\end{tabular}

Abbreviations: BMI = body mass index; HIT-6 = 6-item Headache Impact Test.

Values are mean (SD) or $\mathrm{n}(\%)$.

a Data presented in the intention-to-treat population (included all the patients who underwent randomization).

${ }^{\mathrm{b}}$ A headache day was defined as a calendar day in which the headache pain lasted at least 4 consecutive hours with a peak severity of at least moderate level, or a day when acute migraine-specific medication (triptans or ergots) was used to treat a headache of any severity or duration.

c A migraine day was defined as a calendar day in which headache pain lasted at least 4 consecutive hours and met criteria for migraine (with or without aura) or probable migraine (subtype in which only 1 migraine criterion is absent), or a day when migraine-specific medication (triptans or ergots) was used to treat a headache of any severity or duration.

${ }^{d}$ The HIT-6 questionnaire assesses headache-related disability in the preceding 4 weeks, with scores ranging from 36 to 78 and with scores of 60 or higher reflective of greater disability.

PGIC scores $\geq 5$ were observed (55\% and 54\% for fremanezumab quarterly and monthly vs $37 \%$ for placebo; $p<0.0001$ for both).

\section{Improvement in productivity}

Significant improvements in productivity, from baseline (day 0 ) to 4 weeks after administration of the last dose, were seen with fremanezumab treatment compared with placebo across the 4 dimensions of the WPAI:GH scale (figure 5). Patients who received fremanezumab also reported significant reductions from baseline in overall work productivity loss than those who received placebo (quarterly: $-16.6 \%, p=0.0009$; monthly: $-15.9 \%, p=0.0026$; placebo: $-9.1 \%)$. Similarly, patients treated with fremanezumab quarterly or monthly reported significant reductions from baseline in presenteeism than those who received placebo (fremanezumab quarterly: $-15.7 \%, p=0.0049$; fremanezumab monthly: $-14.9 \%, p=$ 0.0169; placebo: $-10.0 \%)$. There were no significant differences in absenteeism for either treatment group compared with placebo, despite a nonsignificant trend in the monthly fremanezumab administration group (quarterly: $-0.1 \%, p=0.5918$; monthly: $-2.1 \%, p=0.0873$; placebo: $0.8 \%)$. Nevertheless, fremanezumab significantly reduced impairment of activity outside of work in patients who received fremanezumab quarterly compared with placebo (fremanezumab quarterly: $-15.0 \%, p=0.0311$; monthly: $-12.9 \%, p=0.3230$; placebo: $-11.0 \%)$.

\section{Discussion}

The results presented here demonstrate that fremanezumab quarterly or monthly improved migraine-specific quality of life, overall health status, patients' global impression of change, and productivity in patients with CM. Taken in combination with the reduction in number of headache days 
Figure 2 Effect of fremanezumab on health-related quality of life as measured with the Migraine-Specific Quality of Life

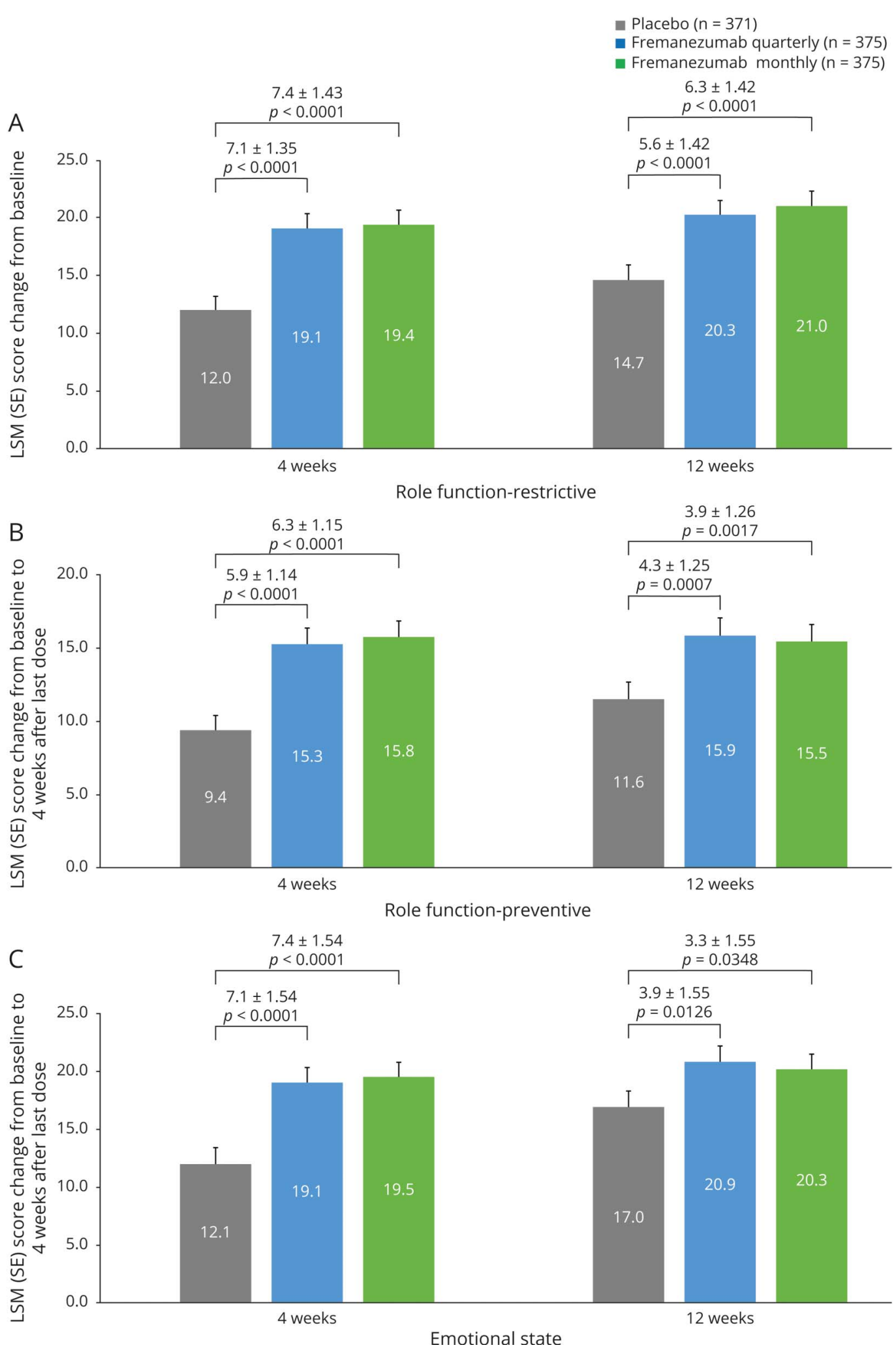

(A) Role function-restrictive. (B) Role function-preventive. (C) Emotional function. LSM = least-squares mean.

demonstrated in the HALO CM trial ${ }^{22}$ and an increase in number of headache-free days with normal functional performance observed in an analysis of a preceding phase 2 trial, ${ }^{29}$ these results demonstrate that fremanezumab quarterly or monthly is an effective and well-tolerated treatment for patients with CM. Convergence of evidence from both 
Figure 3 Effect of fremanezumab on general health state as measured with the EuroQoL 5-dimension, 5-response level

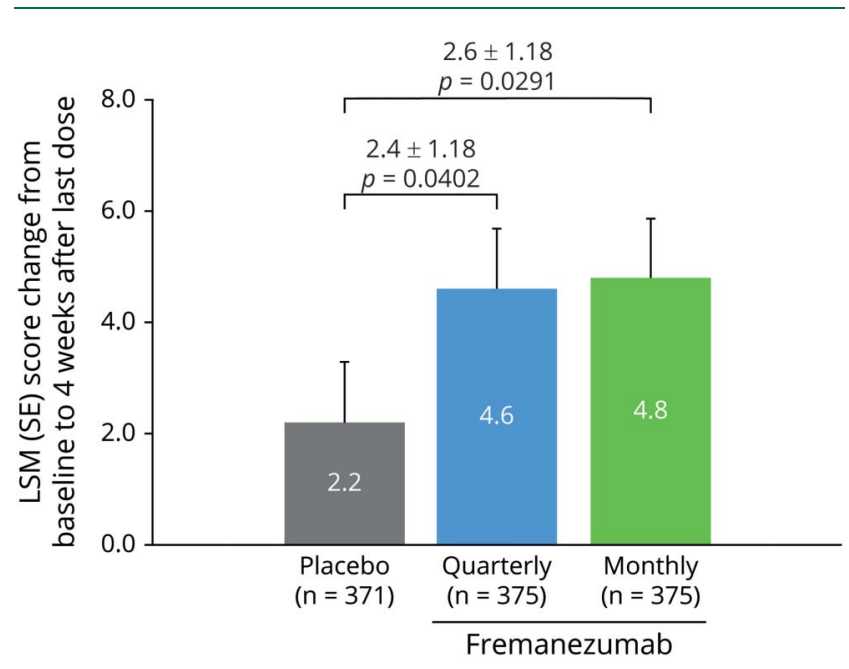

$\mathrm{LSM}=$ least-squares mean.

patient-reported outcomes and more traditional efficacy measures of headache-free days supports the efficacy of fremanezumab in the treatment of $\mathrm{CM}^{22,30}$ The effect of migraine and response to preventive treatments is best understood not just by measures of migraine or headache day frequency, but by multidimensional patient assessments that include subjective emotional experience, disability, comorbidities, and effect of migraine on work and everyday activities. $^{22,31}$
Fremanezumab was associated with statistically significant improvements in all MSQoL domains (i.e., role functionrestrictive, role function-preventive, and emotional function), ${ }^{24}$ with these improvements seen as early as week 4 and maintained through week 12 . Clinically meaningful improvements were observed for role function-restrictive at weeks 4 and 12 . The role function-restrictive domain measures the restriction in daily life activities due to migraine, including the effect on relationships with family and friends, interference in leisure time activities, and the ability to concentrate on work or activities, indicating these factors were improved with fremanezumab. Similarly, clinically meaningful improvements were observed in the role function-preventive domain (the magnitude of change exceeded the established minimally important difference at week 4). Improvement in the role function-preventive domain indicates that patients were able to undertake more daily life activities that had been previously prevented by migraine (e.g., a reduced need to cancel or stop work or activities, ask for help in handling routine tasks, or avoid social activities). ${ }^{32}$ Emotional function improved after treatment with fremanezumab, indicating that patients felt less of an emotional effect of migraine, including feeling less frustration, feeling less burdensome to others, and feeling less afraid of letting others down. ${ }^{32}$ The MSQoL has been used in many studies, and improvement in scores has been shown to be an effective measure of treatment outcomes for migraine and $\mathrm{CM}^{32}$ The significant improvement in MSQoL after fremanezumab treatment is also consistent with previously reported score improvements with fremanezumab on the HIT-6 questionnaire, a tool that reliably assesses headache-related disability and headache-specific impact. ${ }^{22,33}$ Taken together, these results show that patients with $\mathrm{CM}$

Figure 4 Proportion of patients who reported Patient Global Impression of Change (PGIC) scores $\geq 5$

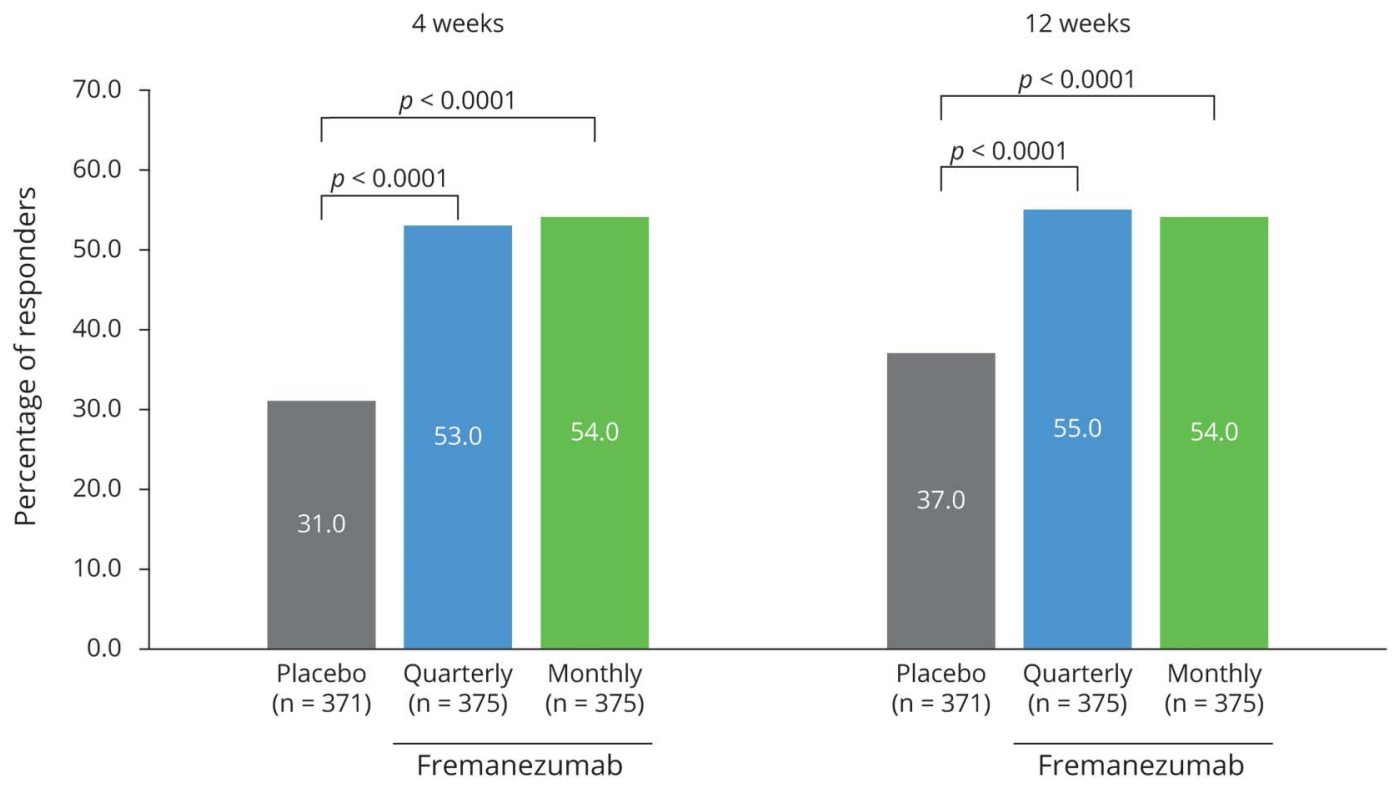

PGIC ratings are based on a 7-point scale (1, no change; 2 , almost the same; 3 , a little better; 4, somewhat better; 5 , moderately better; 6 , better; 7 , a great deal better). 
Figure 5 Effect of fremanezumab on work productivity and activity impairment as measured with the Work Productivity and Activity Impairment: General Health

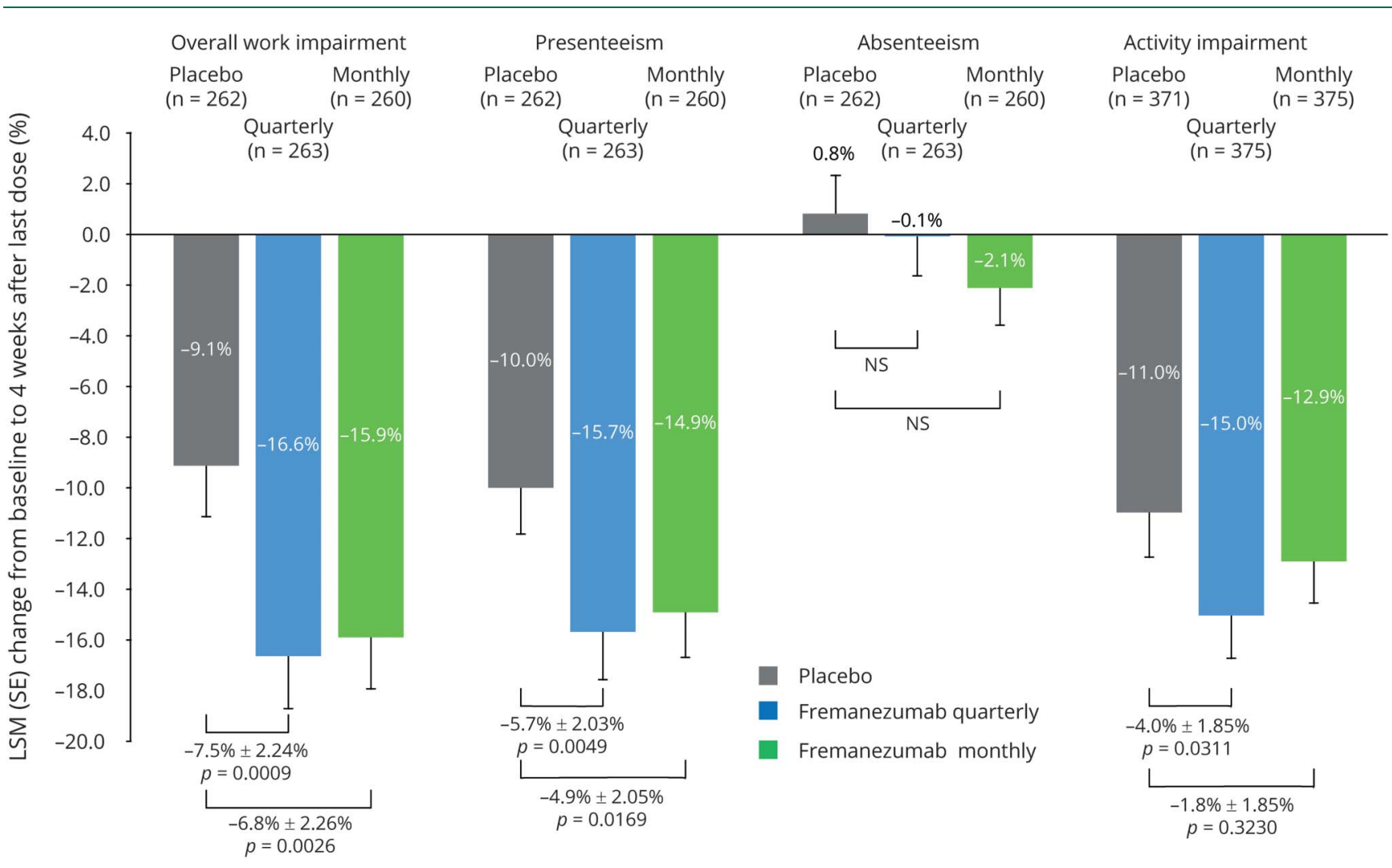

Overall work impairment, presenteeism, and absenteeism $\mathrm{n}$ values represent patients who were employed at week 12 . Activity impairment $\mathrm{n}$ values represent full analysis set population. LSM = least-squares mean.

treated with fremanezumab experience significant and meaningful improvements in quality of life, and find more opportunities to engage in their everyday activities.

Overall patient health state was measured using the EQ-5D$5 \mathrm{~L}$ questionnaire. The EQ-5D-5L questionnaire has often been used in health technology assessments and population health surveys. Fremanezumab quarterly or monthly led to significant improvements in the EQ-5D-5L score, compared with placebo. Given that $\mathrm{CM}$ is associated with a high prevalence of comorbidities, ${ }^{34}$ improvement in overall health status may have particular relevance in this patient population. Further study may be useful to elucidate whether part of the improvement in overall health status is associated with improvement in those comorbidities.

Global rating of change scales are often used in clinical research, and clinicians often ask their patients to rate the change in their condition with treatment. ${ }^{35}$ Here, the PGIC scale was used to measure the patients' global assessment of this change after fremanezumab treatment. A significantly greater proportion of patients treated with either dose of fremanezumab reported that they felt "moderately better," "better," or "a great deal better," compared with patients treated with placebo. These results were observed at the first assessment after the first dose (week 4) and were maintained till the end-of-treatment visit (week 12), indicating that patients assessed their condition as improved over the course of treatment. ${ }^{36}$ The patient's perception of change and treatment effect may be particularly important for medication adherence. Adherence to oral migraine preventive medications is low, even among patients with CM, with rates between $26 \%-29 \%$ at 6 months and $17 \%-20 \%$ at 12 months. ${ }^{37}$ Treatment efficacy and patients' perception of treatment efficacy have been associated with treatment adherence. $^{38,39}$

Fremanezumab quarterly or monthly also resulted in improved scores in the overall work impairment and presenteeism measures of the WPAI:GH questionnaire, compared with placebo, at final visit/end of treatment (4 weeks after the final dose). These are consistent with the other patient-reported outcomes in this study, including improved HRQoL and overall health status in patients being treated with fremanezumab. Presenteeism is a risk factor for future work absence and poor self-rated health over time. ${ }^{40,41}$ Therefore, reducing work impairment and presenteeism may have meaningful effects not just for companies, but for patients themselves. From a societal perspective, improved work productivity and reduced presenteeism may indirectly 
decrease the economic burden of CM. Estimates for the total annual cost of migraine are $\$ 78$ billion in the United States and $€ 111$ billion in the European Union. ${ }^{42,43}$ Indirect costs such as loss of productivity account for up to $70 \%$ of total CMrelated annual costs in the United States and over 90\% of total migraine-related annual costs in Europe. ${ }^{42,44}$ Taken together, the results of this study suggest that fremanezumab has the potential to reduce the significant economic burden of CM on both patients and society.

It is not clear why fremanezumab had no improvements in regards to absenteeism, although fremanezumab quarterly in employed patients led to increased activity outside of work, as compared with placebo. Previous research has shown that the majority of lost productivity in patients with migraine is due to reduced performance while at work, also known as presenteeism. $^{45}$

It is possible that patients with CM have developed other means to reduce absenteeism, leading to lower baseline absenteeism and thus presenting a challenge in noting changes from baseline, while these patients still have high levels of presenteeism. ${ }^{45}$ Therefore, measurements of presenteeism might be better indicators of the effect of a treatment than the measure of absenteeism, which may have a floor effect.

The 2018 Guidelines of the International Headache Society continue to recommend headache frequency as the primary endpoint for controlled trials of preventive treatment of $\mathrm{CM}^{15}$; however, this does not fully capture the benefits of treatment. Fremanezumab did indeed show positive outcomes for such a recommended primary endpoint of reduction in monthly headache days, ${ }^{22}$ and this is aligned with the positive patient-reported outcome measures reported here during the same time course. Similar associations between reduction in headache day frequency and improvements in patient-reported outcome measures have been shown for other treatments, including onabotulinumtoxin $\mathrm{A}$ for $\mathrm{CM},{ }^{46,47}$ topiramate for $\mathrm{CM}^{48}$ and erenumab for $\mathrm{EM}^{49}$ Although it is expected that the reduction in headache days produces these improved patient-reported outcomes, it is also possible that an indirect association exists and that certain aspects of patient-reported outcome measures capture treatment effects that are at least partially independent of headache frequency. Comorbidities, subclinical depression/anxiety symptoms, personality, and psychological or behavioral coping skills of patients with migraine are all likely to be relevant to the quality of life measures reported here, and it is possible that improvements in these elements may partially explain the improvements in the patient-reported outcomes independently of attack frequency.

This study has limitations. There was a substantial placebo effect both on change in monthly migraine and headache days and on patient-reported outcomes. The patient-reported outcome measures, which were part of the prespecified exploratory objectives of the HALO CM study, only measured the outcomes up to 4 weeks after last study drug administration. Longer-term data and data from future real-world studies on the effects of fremanezumab on patient functioning will provide further evidence on the value of this treatment in improving patient outcomes. The results presented here are from multiple comparisons without adjustment in the threshold for significance; these comparisons were all prespecified.

This study reports significant improvements in established patient-reported outcome measures with both fremanezumab quarterly and monthly dosing, allowing clinicians and patients flexibility in the dosing schedule. Fremanezumab, which has an established efficacy and safety profile in treating CM, also improves migraine-specific quality of life, overall health status, patient's global impression of change in overall status with treatment, and productivity and activity impairment in patients with CM. These improvements highlight the importance of assessing the patient wholly, including both headache days and quality of life, in order to guide treatment. Further, they give hope to both patient and society that the burden of CM can be substantially reduced and quality of life improved.

\section{Acknowledgment}

Editorial assistance, including assistance with incorporating the authors' edits, checking references, and comparing figures and tables with the study report, was provided by Mary Clare Kane and Sarah Qamar of Chameleon Communications International. This assistance was in accordance with Good Publication Practice (GPP3) guidelines and funded by Teva Pharmaceuticals. The authors maintained full editorial control of the manuscript and decision to submit for publication.

\section{Study funding}

This study was funded by Teva Pharmaceutical Industries Ltd., Petach Tikva, Israel.

\section{Disclosure}

R. Lipton receives research support from the NIH: 2PO1 AG003949 (Program Director), 5 U10 NS077308 (PI), RO1 NS082432 (Investigator), 1RF1 AG057531 (Site PI), RF1 AG054548 (Investigator), 1RO1 AG048642 (Investigator), R56 AG057548 (Investigator), K23 NS09610 (Mentor), K23AG049466 (Mentor), 1K01AG054700 (Mentor). He also receives support from the Migraine Research Foundation and the National Headache Foundation. He serves on the editorial board of Neurology ${ }^{\circledR}$, as senior advisor to Headache, and as associate editor of Cephalalgia. He has reviewed for the NIA and NINDS; holds stock options in eNeura Therapeutics and Biohaven Holdings; and serves as consultant, advisory board member, or has received honoraria from American Academy of Neurology, Alder, Allergan, American Headache Society, Amgen, Autonomic Technologies, Avanir, Biohaven, Biovision, Boston Scientific, Dr. Reddy's, electroCore, Eli Lilly, eNeura Therapeutics, GlaxoSmithKline, Merck, Pernix, Pfizer, Supernus, Teva, Trigemina, Vector, and Vedanta. He 
receives royalties from Wolff's Headache 7th and 8th Edition, Oxford University Press, 2009, Wiley and Informa. J. Cohen: employee of Teva Branded Pharmaceutical Product R\&D, Inc (USA). S. Gandhi: employee of Teva Branded Pharmaceutical Product R\&D, Inc (USA). R. Yang: former employee of Teva Pharmaceutical Industries Ltd. P. Yeung: former employee of Teva Pharmaceutical Industries Ltd. D. Buse: consultant to Amgen/Novartis, Allergan, Avanir, Biohaven, Eli Lilly, Promius/Dr. Reddy's, and Teva Pharmaceutical Industries Ltd. Go to Neurology.org/N for full disclosures.

\section{Publication history}

Received by Neurology July 31, 2019. Accepted in final form January 28, 2020.

Appendix Authors

\begin{tabular}{lll}
\hline Name & Location & Contribution \\
\hline Richard B. & Albert Einstein College of & Acquisition, analysis, or \\
Lipton, MD & $\begin{array}{l}\text { Medicine and Montefiore } \\
\text { Headache Center, Bronx, }\end{array}$ & $\begin{array}{l}\text { interpretation of data; } \\
\text { drafting of the manuscript; } \\
\text { critical revision of the } \\
\text { NY }\end{array}$ \\
& & $\begin{array}{l}\text { manuscript for important } \\
\text { intellectual concepts }\end{array}$
\end{tabular}

\begin{tabular}{ll}
\hline Joshua M. & Teva Pharmaceutical \\
Cohen, MD, & Industries Ltd., West \\
MPH, FAHS & Chester, PA
\end{tabular}

Acquisition, analysis, or interpretation of data; drafting of the manuscript; critical revision of the manuscript for important intellectual concepts

\begin{tabular}{lll}
\hline Sanjay K. & Teva Pharmaceutical & Concept and design; \\
Gandhi, PhD & Industries Ltd., West & acquisition, analysis, or \\
& interpretation of data; \\
& drafting of the manuscript; & \\
& & critical revision of the \\
& manuscript for important \\
& intellectual concepts
\end{tabular}

Ronghua Teva Pharmaceutical

Yang, PhD Industries Ltd., West Chester, PA

Concept and design;
acquisition, analysis, or
interpretation of data;
statistical analysis; drafting
of the manuscript; critical
revision of the manuscript
for important intellectual
concepts

\begin{tabular}{ll}
\hline Paul P. & Teva Pharmaceutical \\
Yeung, MD, & Industries Ltd., West \\
MPH, FAHS & Chester, PA
\end{tabular}

Concept and design; acquisition, analysis, or interpretation of data; drafting of the manuscript; critical revision of the manuscript for important intellectual concepts

\begin{tabular}{lll}
\hline Dawn C. & Albert Einstein College of & Acquisition, analysis, or \\
Buse, PhD & Medicine, Bronx, NY & interpretation of data; \\
& drafting of the manuscript; \\
& critical revision of the \\
& manuscript for important \\
& intellectual concepts
\end{tabular}

\section{References}

1. GBD 2016 Headache Collaborators. Global, regional, and national burden of migraine and tension-type headache, 1990-2016: a systematic analysis for the Global Burden of Disease Study 2016. Lancet Neurol 2018;17:954-976.

2. GBD 2016 Disease and Injury Incidence and Prevalence Collaborators. Global, regional, and national incidence, prevalence, and years lived with disability for 328 diseases and injuries for 195 countries, 1990-2016: a systematic analysis for the Global Burden of Disease Study 2016. Lancet 2017;390:1211-1259.

3. Leonardi M, Steiner TJ, Scher AT, Lipton RB. The global burden of migraine: measuring disability in headache disorders with WHO's Classification of Functioning, Disability and Health (ICF). J Headache Pain 2005;6:429-440.

4. Saylor D, Steiner TJ. The global burden of headache. Sem Neurol 2018;38:182-190.

5. Steiner TJ, Stovner LJ, Vos T, Jensen R, Katsarava Z. Migraine is first cause of disability in under 50s: will health politicians now take notice?. J Headache Pain 2018; 19:17.

6. Buse DC, Manack AN, Fanning KM, et al. Chronic migraine prevalence, disability, and sociodemographic factors: results from the American Migraine Prevalence and Prevention Study. Headache 2012;52:1456-1470.

7. Hawkins K, Wang S, Rupnow MF. Indirect cost burden of migraine in the United States. J Occup Environ Med 2007;49:368-374.

8. Buse DC, Manack A, Serrano D, Turkel C, Lipton RB. Sociodemographic and comorbidity profiles of chronic migraine and episodic migraine sufferers. J Neurol Neurosurg Psychiatry 2010;81:428-432.

9. Blumenfeld AM, Varon SF, Wilcox TK, et al. Disability, HRQoL and resource use among chronic and episodic migraineurs: results from the International Burden of Migraine Study (IBMS). Cephalalgia 2011;31:301-315.

10. Buse D, Manack A, Serrano D, et al. Headache impact of chronic and episodic migraine: results from the American Migraine Prevalence and Prevention study. Headache 2012;52:3-17.

11. Buse DC, Scher AI, Dodick DW, et al. Impact of migraine on the family: perspectives of people with migraine and their spouse/domestic partner in the CaMEO study. Mayo Clin Proc 2016;91:596-611.

12. Stokes M, Becker WJ, Lipton RB, et al. Cost of health care among patients with chronic and episodic migraine in Canada and the USA: results from the International Burden of Migraine Study (IBMS). Headache 2011;51:1058-1077.

13. Aurora SK, Dodick DW, Turkel CC, et al. OnabotulinumtoxinA for treatment of chronic migraine: results from the double-blind, randomized, placebo-controlled phase of the PREEMPT 1 trial. Cephalalgia 2010;30:793-803.

14. Diener HC, Dodick DW, Aurora SK, et al. OnabotulinumtoxinA for treatment of chronic migraine: results from the double-blind, randomized, placebo-controlled phase of the PREEMPT 2 trial. Cephalalgia 2010;30:804-814.

15. Tassorelli C, Diener HC, Dodick DW, et al. Guidelines of the International Headache Society for controlled trials of preventive treatment of chronic migraine in adults. Cephalalgia 2018;38:815-832.

16. Bagley CL, Rendas-Baum R, Maglinte GA, et al. Validating Migraine-Specific Quality of Life Questionnaire v2.1 in episodic and chronic migraine. Headache 2012;52: 409-421.

17. Reilly MC, Zbrozek AS, Dukes EM. The validity and reproducibility of a work productivity and activity impairment instrument. Pharmacoeconomics 1993;4: 353-365.

18. Herdman M, Gudex C, Lloyd A, et al. Development and preliminary testing of the new five-level version of EQ-5D (EQ-5D-5L). Qual Life Res 2011;20:1727-1736.

19. AJOVY $^{\circledast}$ (Fremanezumab) [prescribing information]. Frazer: Teva Pharmaceuticals USA, Inc.; 2018.

20. AJOVY $^{\circledast}$ (Fremanezumab) [summary of product characteristics]. Frazer: Teva Pharmaceuticals GmbH; 2019.

21. Hoy SM. Fremanezumab: first global approval. Drugs 2018;78:1829-1834.

22. Silberstein SD, Dodick DW, Bigal ME, et al. Fremanezumab for the preventive treatment of chronic migraine. N Engl J Med 2017;377:2113-2122.

23. Silberstein SD, Holland S, Freitag F, et al. Evidence-based guideline update: pharmacologic treatment for episodic migraine prevention in adults: report of the Quality Standards Subcommittee of the American Academy of Neurology and the American Headache Society. Neurology 2012;78:1337-1345.

24. Cole JC, Lin P, Rupnow MF. Minimal important differences in the Migraine-Specific Quality of Life Questionnaire (MSQ) version. Cephalalgia 2009;29:1180-1187.

25. van Reenen M, Janssen B. EQ-5D-5L User Guide. Basic Information on How to Use the EQ-5D-5L Instrument, version 2.1. Available at: euroqol.org/wp-content/ uploads/2016/09/EQ-5D-5L_UserGuide_2015.pdf. Accessed January 1, 2019.

26. Zhang H, Lian Y, Ma Y, et al. Two doses of botulinum toxin type A for the treatment of trigeminal neuralgia: observation of therapeutic effect from a randomized, doubleblind, placebo-controlled trial. J Headache Pain 2014;15:65.

27. Salem H, Pigott T, Zhang XY, Zeni CP, Teixeira AL. Antipsychotic-induced tardive dyskinesia: from biological basis to clinical management. Expert Rev Neurother 2017; 17:883-894.

28. Stender M, Bryant-Comstock L, Phillips S. Medical resource use among patients treated for bipolar disorder: a retrospective, cross-sectional, descriptive analysis. Clin Ther 2002;24:1668-1676.

29. VanderPluym J, Dodick DW, Lipton RB, Ma Y, Loupe PS, Bigal ME. Fremanezumab for preventive treatment of migraine: functional status on headache-free days. Neurology 2018;91:e1152-e1165.

30. US Department of Health and Human Services, Food and Drug Administration, Center for Drug Evaluation and Research (CDER), Center for Biologics Evaluation and Research (CBER), Center for Devices and Radiological Health (CDRH). Guidance for Industry Patient-Reported Outcome Measures: Use in Medical Product Development to Support Labeling Claims. Silver Spring: Division of Drug Information Center for Drug Evaluation and Research Food and Drug Administration; 2009.

31. D'Amico D, Tepper SJ. Prophylaxis of migraine: general principles and patient acceptance. Neuropsychiatr Dis Treat 2008;4:1155-1167. 
32. Rendas-Baum R, Bloudek LM, Maglinte GA, Varon SF. The psychometric properties of the Migraine-Specific Quality of Life Questionnaire version 2.1 (MSQ) in chronic migraine patients. Qual Life Res 2013;22:1123-1133.

33. Haywood KL, Mars TS, Potter R, Patel S, Matharu M, Underwood M. Assessing the impact of headaches and the outcomes of treatment: a systematic review of patientreported outcome measures (PROMs). Cephalalgia 2018;38:1374-1386.

34. Manack AN, Buse DC, Lipton RB. Chronic migraine: epidemiology and disease burden. Curr Pain Headache Rep 2011;15:70-78.

35. Kamper SJ, Maher CG, Mackay G. Global rating of change scales: a review of strengths and weaknesses and considerations for design. J Man Manip Ther 2009; 17:163-170.

36. Dworkin RH, Turk DC, Farrar JT, et al. Core outcome measures for chronic pain clinical trials: IMMPACT recommendations. Pain 2005;113:9-19.

37. Hepp Z, Dodick DW, Varon SF, Gillard P, Hansen RN, Devine EB. Adherence to oral migraine-preventive medications among patients with chronic migraine. Cephalalgia 2015;35:478-488.

38. Brown MT, Bussell JK. Medication adherence: WHO cares? Mayo Clin Proc 2011;86: 304-314.

39. Blumenfeld AM, Bloudek LM, Becker WJ, et al. Patterns of use and reasons for discontinuation of prophylactic medications for episodic migraine and chronic migraine: results from the second international burden of migraine study (IBMS-II). Headache 2013;53:644-655.

40. Bergstrom G, Bodin L, Hagberg J, Lindh T, Aronsson G, Josephson M. Does sickness presenteeism have an impact on future general health? Int Arch Occup Environ Health 2009;82:1179-1190.
41. Bergstrom G, Bodin L, Hagberg J, Aronsson G, Josephson M. Sickness presenteeism today, sickness absenteeism tomorrow? A prospective study on sickness presenteeism and future sickness absenteeism. J Occup Environ Med 2009;51:629-638.

42. Gooch CL, Pracht E, Borenstein AR. The burden of neurological disease in the United States: a summary report and call to action. Ann Neurol 2017;81:479-484.

43. Linde M, Gustavsson A, Stovner LJ, et al. The cost of headache disorders in Europe: the Eurolight project. Eur J Neurol 2012;19:703-711.

44. Agosti R. Migraine burden of disease: from the patient's experience to a socioeconomic view. Headache 2018;58(suppl 1):17-32.

45. Serrano D, Manack AN, Reed ML, Buse DC, Varon SF, Lipton RB. Cost and predictors of lost productive time in chronic migraine and episodic migraine: results from the American Migraine Prevalence and Prevention (AMPP) Study. Value Health 2013;16:31-38.

46. Boudreau GP, Grosberg BM, McAllister PJ, Lipton RB, Buse DC. Prophylactic onabotulinumtoxinA in patients with chronic migraine and comorbid depression: an open-label, multicenter, pilot study of efficacy, safety and effect on headache-related disability, depression, and anxiety. Int J Gen Med 2015;8:79-86.

47. Lipton RB, Rosen NL, Ailani J, DeGryse RE, Gillard PJ, Varon SF. OnabotulinumtoxinA improves quality of life and reduces impact of chronic migraine over one year of treatment: pooled results from the PREEMPT randomized clinical trial program. Cephalalgia 2016;36:899-908.

48. Mathew NT, Jaffri SF. A double-blind comparison of onabotulinumtoxinA (BOTOX) and topiramate (TOPAMAX) for the prophylactic treatment of chronic migraine: a pilot study. Headache 2009;49:1466-1478.

49. Overeem LH, Neeb L, Reuter U. Erenumab for episodic migraine prophylaxis. Expert Rev Neurother 2019;19:751-757. 


\section{Neurology}

\section{Effect of fremanezumab on quality of life and productivity in patients with chronic migraine \\ Richard B. Lipton, Joshua M. Cohen, Sanjay K. Gandhi, et al.}

Neurology 2020;95;e878-e888 Published Online before print August 3, 2020

DOI 10.1212/WNL.0000000000010000

This information is current as of August 3, 2020

\section{Updated Information \& Services}

References

Citations

Subspecialty Collections

Permissions \& Licensing

Reprints including high resolution figures, can be found at: http://n.neurology.org/content/95/7/e878.full

This article cites 45 articles, 3 of which you can access for free at: http://n.neurology.org/content/95/7/e878.full\#ref-list-1

This article has been cited by 1 HighWire-hosted articles: http://n.neurology.org/content/95/7/e878.full\#\#otherarticles

This article, along with others on similar topics, appears in the following collection(s):

\section{All Clinical trials}

http://n.neurology.org/cgi/collection/all_clinical_trials

All Headache

http://n.neurology.org/cgi/collection/all_headache

Clinical trials Randomized controlled (CONSORT agreement)

http://n.neurology.org/cgi/collection/clinical_trials_randomized_contro

lled_consort_agreement

Migraine

http://n.neurology.org/cgi/collection/migraine

Quality of life

http://n.neurology.org/cgi/collection/quality_of_life

Information about reproducing this article in parts (figures,tables) or in its entirety can be found online at:

http://www.neurology.org/about/about_the_journal\#permissions

Information about ordering reprints can be found online:

http://n.neurology.org/subscribers/advertise

Neurology ${ }^{\circledR}$ is the official journal of the American Academy of Neurology. Published continuously since 1951, it is now a weekly with 48 issues per year. Copyright Copyright ( 2020 The Author(s). Published by Wolters Kluwer Health, Inc. on behalf of the American Academy of Neurology.. All rights reserved. Print ISSN: 0028-3878. Online ISSN: 1526-632X.

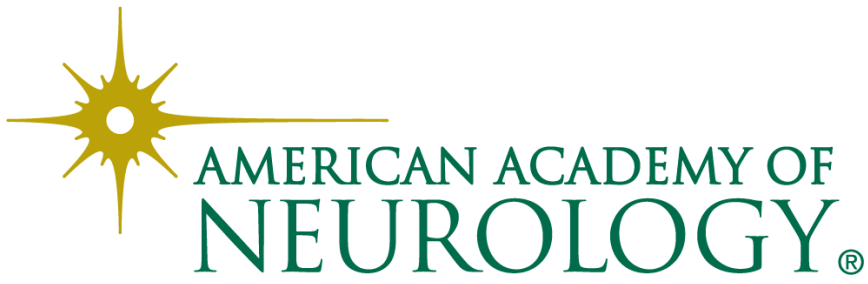

